\title{
ТОM \\ Storytelling for narrative approaches in citizen science: towards a generalized model
}

\author{
Anett Richter, Andrea Sieber, Julia Siebert, \\ Victoria L. Miczajka-Rußmann, Jörg Zabel, David Ziegler, \\ Susanne Hecker and Didone Frigerio
}

Abstract

Keywords

DOI
Storytelling essentials are stories that direct attention, trigger emotions, and prompt understanding. Citizen science has recently promoted the narrative approach of storytelling as a means of engagement of people of all ages and backgrounds in scientific research processes. We seek understanding about the typology of storytelling in citizen science projects and explore to what extent the tool of storytelling can be conceptualized in the approach of citizen science. In a first step, we investigated the use and integration of storytelling in citizen science projects in the three European German-speaking countries. We conducted a low threshold content analysis of 209 projects listed on the German-speaking online platforms for citizen science projects "Bürger schaffen Wissen", "Österreich forscht", and "Schweiz forscht". Two expert workshops with citizen science practitioners were held to validate and discuss the identified role of stories in the practice of citizen science. Our analysis revealed three major categories mirroring how stories are being integrated and applied in citizen science. The first category refers to projects, in which stories are the core research objective. The second category is characterized by the application of stories in different phases of the research project. The third category encompasses stories as agents being part of the communication and organization of the project. We illustrate the practical application of these categories by three representative case studies. By combining the functionality of the categories and abstracting the linkages between storytelling and citizen science, we derived a generalized model accounting for those linkages. In conclusion, we suggest that storytelling should be a prerequisite to enhance the competencies of the actors involved and to exchange knowledge at the interfaces of science and policy as well as science and society.

Citizen science; Science communication: theory and models

https://doi.org/10.22323/2.18060202

Submitted: 12th April 2019

Accepted: 14th October 2019

Published: 12th November 2019 
Stories are narratives that direct attention, trigger emotions and prompt understanding [Bruner, 1996; Wilson, 2002; Echterhoff and Straub, 2003]. They are an expression of art and heritage and connect people with all senses [van der Hoeven, 2019; Walters and Insch, 2018]. Stories are communicated and transferred from generation to generation whereas the contents can either be true or fictitious, but typically designed to trigger interests, amusement or reflection. Stories feature the presence and deliberate use of emotional components prompting emotions such as humour, pain or joy. Storytelling as a narrative method refers to "narrating into a story" and to a much lower extent to "telling and listening to a story" [Ingrisch, Mangelsdorf and Dressel, 2017]. Storytelling as a method is embedded in cultural and social contexts and is used to share stories. Reduced to its basics, a story includes features with the main character as a hero, a plot for the story and a narrative approach including a conflict that needs to be solved by the hero.

\section{Storytelling in education}

All sciences are cultural enterprises owing their achievements not only to the pure application of scientific methodologies but also to various particulars, coincidences and personal construal of meaning [Chinthamani, 2003]. In other words: science requires rational and non-narrative thinking, but because stories are so prevalent in our minds, they are embedded in the scientific culture and used as multipliers of scientific content. Thus, it is not surprising that storytelling is a well-established tool in the fields of science education [Bruner, 1996; Zabel and Gropengießer, 2015] and science communication [Dahlstrom, 2014]. In science education, the power of stories receives particular acknowledgement by being a part of curricular recommendations [Osborne, 1998; Norris et al., 2005]. For instance, science teachers apply storytelling to wrap complex scientific relationships in a compact and appealing format [Kahlert, 2005]. Further, the tool may be used to contextualize the authentic scientific idea with historical aspects or aspects of everyday human life, thereby enhancing the students' motivation via a so-called "narrative effect" [Norris et al., 2005]. Science teachers are encouraged to train their audiences to work consciously with both forms of reality - the narrative and the scientific one [Bruner, 1996; Kurth et al., 2002]. However, understanding and sharing of narratives might be restricted by familiar, cultural and even institutional habits, thus potentially limiting their general applicability [Woods, 2011].

\section{Storytelling in science communication}

For the field of science communication, storytelling is being investigated and applied by practitioners and researchers [Dahlstrom, 2014] as a tool to communicate science to the public. Narratives already play an important role in scientific processes, especially when it is no longer the only aim to disseminate results within the scientific community but rather to communicate science to a broader public [Dahlstrom, 2014]. Here, stories seem to be easier to understand, thus promoting motivation of the audience to listen to them rather than to the traditional logic-based line of argumentation [Green, 2006; Dahlstrom, 2014]. In a recent editorial, Weitkamp [2016] suggests that research papers should be considered as stories aimed to reach out to a broader public as this would make research better understandable, more transparent and more accessible. Further, research about the effectiveness of storytelling in science communication suggests 
that dialogues among stakeholders or between scientists and the public mature through the stories whilst producing personal responses and emotions to science and scientific facts and topics [Leggett and Finlay, 2001]. Also, processes such as raising awareness, enabling enjoyment, fostering interest, developing opinions and promoting understanding can be triggered through stories [Burns, O'Connor and Stocklmayer, 2003]. Studies illustrate how stories are applied to promote public understanding and changes in attitudes [e.g. Hinyard and Kreuter, 2007], to transfer messages among disciplines and to generate and present data [Hagenhoff et al., 2007]. Furthermore, storytelling is frequently embedded in learning approaches through digital storytelling [e.g. Robin, 2015; Barrett, 2006; Chung, 2007]. Digital storytelling as a field gains greater scholarly attention [Robin, 2016] and application in diverse disciplines, i.e. in mental health research [De Vecchi et al., 2016].

Altogether, storytelling is an inherent tool for communication with great potential to unite disciplines and fields, with interactions between people and the flow of information with between people being of central importance. Thus, understanding the functionality of storytelling requires a multidisciplinary approach. Despite the in-depth knowledge about the role of narratives in science education and science communication, the function of narratives in new forms of public engagement in scientific research, i.e. in citizen science, is relatively unexplored.

\section{Meaning of citizen science}

Citizen science refers to a current momentum creating a partnership between members of the scientific and the social community to generate knowledge, foster scientific literacy and enhance learning through engagement. It also builds social capital through the involvement of citizens of all ages and from all backgrounds along the periphery of the research process [Bonn et al., 2016; Edwards et al., 2018]. Citizen science accentuates research with and for members of society with various topics being addressed by scientists and members of society in a collaborative approach [Bonney et al., 2015]. Further, it expresses a commitment to dialogue among the people involved in this collaboration [Trench, 2008]. This partnership varies with regard to the level and degree of engagement [from contractual to co-created projects, see Shirk et al., 2012] and the time individuals are involved in the activities (ranging from hours to few days and even to decades). The current rise of citizen science projects and the high visibility of citizen science activities on national and international platforms express the professionalization of citizen science. This is appreciated in science, society and politics [Kullenberg and Kasperowski, 2016; Ceccaroni and Piera, 2017; Hecker, Haklay et al., 2018]. Further, at the level of continents and states, dedicated associations have been launched to support and foster citizen science as a field and the community of citizen science practitioners [Göbel et al., 2016].

In tune with the growth of citizen science over the last decades, storytelling as a format in science communication also gained importance and visibility in the practice of citizen science [Hecker, Luckas et al., 2018]. Tools of storytelling and narratives have been applied in citizen science, i.e. to better understand the needs and requirements of the users regarding citizen science technologies [Skarlatidou 
et al., 2019]. Yet, it is applied without the intention of telling a story but also as a tool to evaluate citizen science research [Constant and Roberts, 2017], i.e. storytelling was applied at a reflective meta-level. Communication, in general, plays an essential role in citizen science, e.g. to establish social networks that in turn facilitate long-term engagement, stability and growth of citizen science programs [Richter, Hauck et al., 2018]. Moreover, communication is needed to successfully establish and perform citizen science programs as part of the coordination of these schemes [van Vliet, Bron and Mulder, 2014].

Here, we investigated storytelling as an integrated tool in the practice of citizen science and analyzed the function of storytelling as a narrative approach in citizen science. First, we assessed how frequently storytelling is being applied in citizen science projects in the three German-speaking countries in Europe. Second, case studies supporting and showcasing the emerged categories are presented. Third, we developed a generalized model to conceptualize the role of storytelling in citizen science. We hypothesized that storytelling as a tool is applied in the practice of citizen science as a means to communicate the aims and objectives of the project to the participants as well as to the community outside the project.

Specifically, we addressed the following main questions:

1) To what extent is storytelling applied and integrated into current citizen science projects in the three European German-speaking countries?

2) How can storytelling be conceptualized in citizen science?

3) What can we learn from a conceptualized model of storytelling in citizen science?

Content analysis refers to a scientific method that objectively and systematically examines information from sources of communication such as posters, publications, and the web [Lac, 2016]. We performed a quantitative examination of the text to assess the integration of storytelling in citizen science projects listed on online platforms of the three German-speaking countries (Germany, Austria and Switzerland). The rationale for the selection of these countries was twofold. The selected countries share the same language and a similar history regarding the development of online platforms for citizen science projects and capacity building developments for citizen science [Richter, Dörler et al., 2018]. Online platforms represent the landscape of citizen science at the project level and provide valuable sources of information for scientific investigations [Pettibone, Vohland and Ziegler, 2017]. We considered the projects listed on these platforms as a reliable proxy for current activities and programs in the three countries.

For the scope of this study, we applied the non-random purposive sampling approach by placing a systematic rule in the sampling procedure. The rule included the reduction of the data set (list of projects) for duplicates. Projects that 
were listed at more than one platform were deleted to avoid double counting. For the collection of information, we used websites, accessible online outreach material (flyers, posters), and the project descriptions at the online platforms for citizen science for each of the three countries. We established a list of all projects listed at the platforms "https:/ / www.buergerschaffenwissen.de/" (Germany) "https:/ / www.citizen-science.at/" (Austria) and "https:/ / www.schweiz-forscht.ch/" (Switzerland) at the time around mid-December 2018. Each project was listed by name, country of origin, time of establishment and status (ongoing, time of ending) as well as the geographical scale of the citizen science activity. Further, we listed target groups (when referred to) and summarized the overall aims of the project. Descriptions of all projects (rationale, aims, objectives, methods) were gathered as text.

In a first step, the text passages were subjected to a frequency analysis using keywords. The list of keywords includes the German words: stories (Geschichten, Erzählung), storytelling (Geschichten erzählen), reports (Berichte), reporting (berichten), commenting (kommentieren) and communicating (kommunizieren). The text passages that contained at least one of the keywords were collated in a so-called "codebook". In a second step, categories were developed to assess the role of storytelling in the practice of citizen science using a qualitative-inductive approach [Mayring, 2010]. The development of the codebook and categories was performed by the lead author and controlled for code reliability with the participants of the workshops.

\section{Selection and assignment of case studies}

The categorization of storytelling in citizen science projects was assessed with 20 practitioners in this field in two consecutive expert workshops. Workshop participants were mainly from Germany and Austria. The workshops were conceptualized to exchange experiences regarding the integration of storytelling in citizen science and to assign case studies to the categories developed. During those workshops, we applied a format called "Artful Closer" where an art activity is applied to foster reflections and discussion about the integration of stories in citizen science. The goal of the format was to reflect on the experiences regarding storytelling in citizen science and to share them with the participants. We asked our participants to create small sculptures of clay to visualize the connections of storytelling in citizen science. After the presentations of the creative effort, experiences were exchanged among the participants. The practitioners reflected on the pertinence of storytelling, reported on the increasing confidence when applying it in citizen science and shared their knowledge about the diverse structures and functions of storytelling in citizen science. The workshop closed with a reflection and discussion about the three categories (objectives, tools, agents) and the agreement on the three case studies presented here.

\section{Conceptualizing the model}

Following this evaluation of the identified categories, we performed several steps of abstraction. In practice, this involved the visualization of the categories, discussions about the pathways between them and the reduction of information to finally derive a conceptual framework for storytelling as a narrative approach in 
citizen science. We consider this conceptual framework as a first attempt towards a generalized model aiming to facilitate further investigations about the understanding of the role of storytelling in citizen science.

At the time of the investigation (December 2018), a total of 209 citizen science projects were listed on the three German-speaking platforms. The geographical magnitude of the listed projects ranged from landscapes (e.g. forest, orchard) to the city, state and national levels (see Figure 1). Most projects were carried out on a national level and on the state level (Bundesländer); few projects also involved the European and global geographical scale (see Figure 1). The duration of the projects varied from recently initiated (less than one year) to activities that had been ongoing over several years (more than 10 years) (see Figure 2).

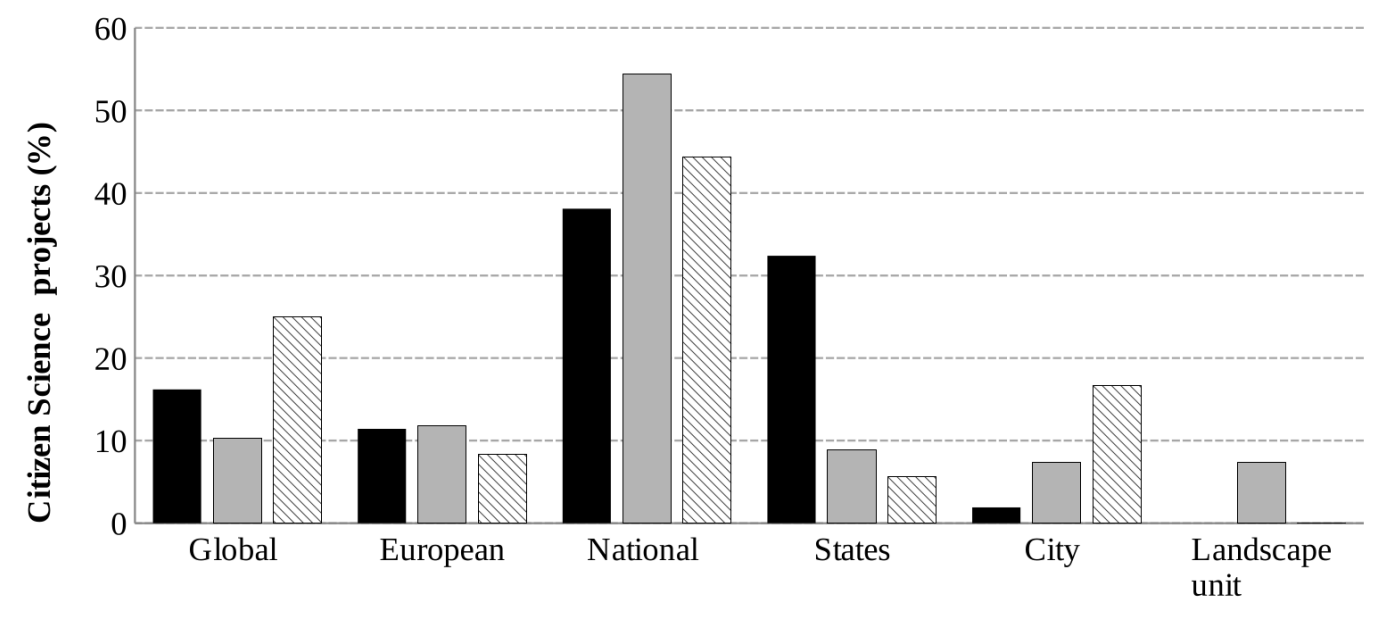

Geographical scales of citizen science projects

—Germany $\square$ Austria $₫$ Switzerland

Figure 1. Distribution of Citizen Science projects (\%) listed in Germany (black), Austria (grey), and Switzerland (shaded) along geographical scales from global, to European, national, state, and city level, as well as the level of landscape units (e.g. forest, lake).

The text analysis revealed that none of the projects explicitly used the English term "storytelling" in its descriptions of aims, objectives and methods. The German translation of the word "storytelling" (Geschichten erzählen) was neither used as a term. The most frequently used term indicating the application or integration of stories was "stories" (Geschichten). We identified three categories that describe the application of stories in citizen science projects: 1) stories acting as objectives, b) stories being applied as tools and c) stories acting as agents (see Figure 3). When stories are integrated as objectives, they express a set of qualitative information that is inherent in the story and lead to the generation of new knowledge and the exchange of existing insights. When stories are applied as tools they function as flexible supportive utensils to assist with the generation of knowledge. When stories are applied as agents they help to convey messages to attract a broad audience. A total of 59 projects out of 209 projects refer to these main categories (objectives, tools, agents). 


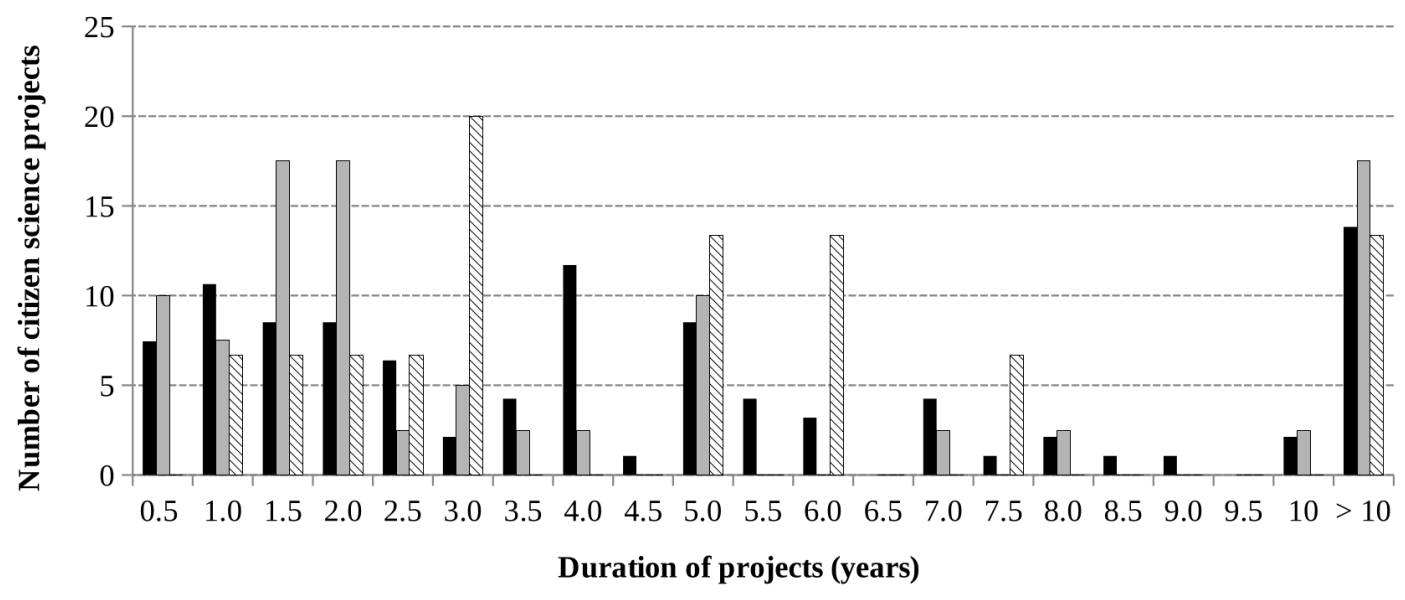

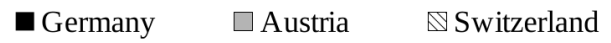

Figure 2. Distribution of projects (total number) in relation to their duration in years for Germany (black), Austria (grey), and Switzerland (shaded).

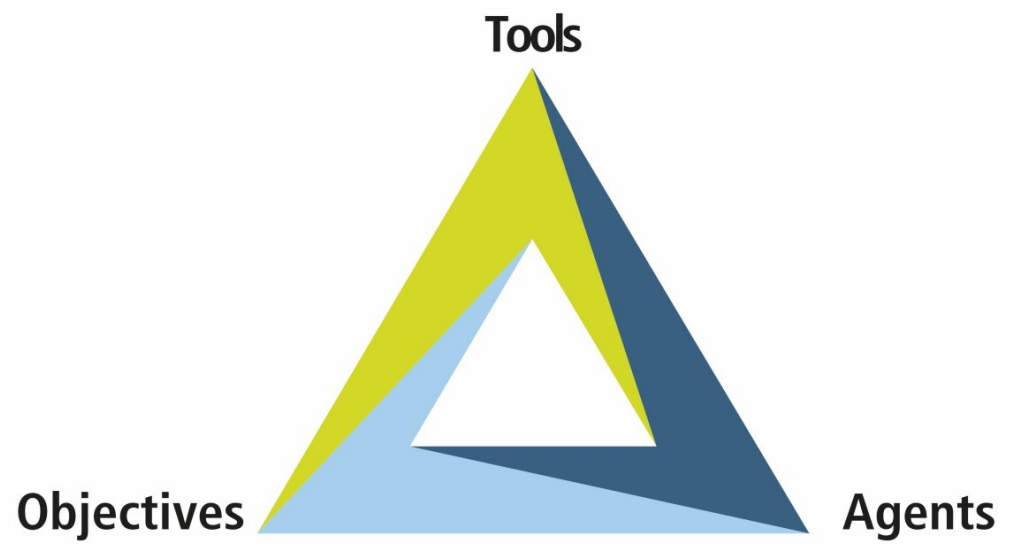

Figure 3. Three main categories identified for storytelling in citizen science projects listed online in German-speaking countries. Storytelling in citizen science can act as an objective (e.g. something to pursue), a tool (e.g. something applied), or/and as an agent (e.g. something causing effects).

\section{Objectives - Tools - Agents}

According to our investigation, projects that apply stories as objectives aim to display and collect existing knowledge from and with written or printed contemporary or historical documents, such as diaries, postcards, newspapers, books, etc. (see Table 1 in appendix A). Stories or fragments of stories are the focus of scientific analysis. For example, the project "Investigation Nightingale" (Forschungsfall Nachtigall) collects stories, songs and poems that are used to analyze the cultural history of the birds. Likewise, the project "Pollen Diary" (Pollentagebuch) collects personal stories about the exposure to pollen, the impact of pollen occurrence and its density to analyze the individual (diverse) effects of such exposure. We identified in total 16 projects that use stories as an objective (see Table 1 in appendix A). 
Stories in citizen science projects are also collected as a tool to form new research questions. For example, the project "Genealogical postcard archive"

(Genealogisches Postkartenarchiv) collects historic handwritten postcards and digitalizes the content. Here, stories act as a tool to gather knowledge about the daily life of ordinary people in the past and build the foundation of new research questions. Such forms of application are found in different disciplines e.g. in participatory health research, oral history, and biodiversity monitoring. The task proposed to citizens in the project "Generation Smartphone" is to document and report stories about the use and the values of mobile devices. Each submitted story is analyzed for values but also risks of the use of smartphones by and with young people and adults. The citizen science project "Care and Heat" applies café talks to gather information from people that care for and look after elderly people, more specifically about their personal experiences regarding the impact of heat on the health and well-being of people. We identified in total 28 projects that used stories as a tool in different phases of a research project; i.e. by identifying or improving the research question, collecting and/or analyzing data, discussing and interpreting results, or when communicating and applying findings (see Table 1 in appendix A).

Stories in citizen science are also embedded within the project to function as an agent. For example, science slams, science cafés or special university programs for children (e.g. KinderUni) are centred on stories. The application of stories aims to reach out to the public, to trigger attention and/or to acquire volunteers as part of the project management. Such applications are often described as "Scienceperience", a combination of science and experience to describe the connection of science with hands-on experience, which leads to sustainable understanding and internalization of the scientific contents [Dernbach, Kleinert and Münder, 2012]. For example, the project "Reparakultur" developed a so-called "Erzählkoffer" - a trolley full of stories. In this case, the stories are used as a vehicle to transport the message of the project: the re-use of products through the process of repairing. We identified 15 projects that fall into the third category in which "telling of and listening to stories" is applied as an agent to allow communication and organization of citizen science projects (see Table 1 in appendix A).

We also discovered that many projects integrate the functions of storytelling in multiple ways. For example, the project "Who cares" applies storytelling as an objective as well as an agent. Others combine the function as objective and tool, e.g. the project "Faces of Migration" (Gesichter der Migration) (see Table 1 in appendix A for more combinations).

\section{Storytelling in the practice of citizen science: presentation of case studies}

To foster the discussion about the role of storytelling in citizen science in practice and to control for code reliability of the three identified categories (objectives, tools, agents), two expert workshops were organized. In total, 20 participants joined the workshops and shared their experiences. Based on the outcomes of the workshops, two conclusions can be drawn. First, the participants agreed with the categories developed and supported them by presenting their own case studies that fit into the categories. Second, it was confirmed that storytelling plays an essential role in 
the practice of citizen science. According to the participants, one of the greatest values of applying stories in citizen science lies within its potential to establish relationships among the people involved in the processes of generating and exchanging knowledge. The practitioners consider these bonds highly important for later commitment to the joint activity. This, in turn, is a basis for collaboration and future engagement in scientific research. Personal and internal perspectives are conveyed through storytelling and make perspectives and views accessible for the participants as well as the scientists. This two-way exchange of perspectives is also perceived as very important by the practitioners as it allows the development of more targeted solutions and approaches by society. Further, the participants indicated the great value of stories to promote ideas, express opinions and act as vehicles to achieve the aims and objectives of the project.

At the workshop, participants identified case studies to illustrate the multiple functions of storytelling in today's citizen science practice. Three case studies are presented to showcase the integration of the categories in more detail. Each case study starts with a short conclusive remark about the role of storytelling, followed by a more detailed description of the project aims and the functions and benefits of the application of storytelling. In the first example, storytelling is the objective of research and addresses the uptake of existing knowledge through intergenerational dialogue. The second example presents storytelling as a tool applied to enhance scientific literacy in natural research. The third case study integrates storytelling as an agent for the communication of scientific results to the public.

\section{Case Study 1: Storytelling as a research objective to investigate the culture of bread}

Storytelling facilitates intergenerational dialogues and, thus, fosters understanding of processes of social change as well as openness to other perspectives, mutual recognition and the formation of one's values and attitudes. Intergenerational dialogues reveal cultural knowledge and social experiences that, in turn, provide insights into the values and attitudes of several generations. The project "BrotZeit" (Time for Bread) was initiated by the Alps-Adria University and local schools (Bildungszentrum Lesachtal, Hermagor) and took place from 2015 to 2017. BrotZeit was a co-creative citizen science project, in which consistent cooperation took place during all phases of the research project - from the development of the proposal and of research questions from the different actors to the project conception, the implementation, the analysis and the presentation of the results. The project focused on the preservation, transfer and transformation of intangible cultural heritage based on the Lesachtal bread, a local speciality. The project investigated pathways of intergenerational transmission of experiential, historical and symbolic knowledge about bread in rural Austria. In this project, stories were the core research objectives to reveal and secure unscripted local and historical knowledge. An initial call to submit stories, pictures or videos about the general topic of bread culture led to an overwhelming number of responses. Over 150 submissions were received following public announcements in the local press, on the project webpage and personalized invitations to all households in the valley. Also, after enrolling in school, scientists trained young people to interview older people serving as a source of knowledge. During later stages of the research process, the qualitative interviews were jointly analyzed and the results prepared according to the target group. Products included an audio guide, an animated film, an 
documentary film, a song, an open-air exhibition for the local population and science, a science slam contribution and a jointly produced scientific paper. The analysis of the stories sent to the researchers revealed a diverse culture of the value and making of bread in the Lesach Valley resulting in a novel understanding about cultural practices and social identity [Strohmeier and Sieber, 2017]. In addition to the value of stories as a research objective to collect and save traditional knowledge, stories proved highly suitable to (re)connect generations. Through the methodology of oral history and the collaboration with older contemporary witnesses, students experienced an interdisciplinary and lively history of everyday life. The older generation also valued the intergenerational exchange of knowledge and felt empowered being included in the research project. Recently, the project received the award as best practice project by the Austrian UNESCO commission and from the Council of Europe $(\mathrm{CoE})$ for the development of novel means to assess and secure culture heritage.

Case Study 2: Storytelling as a tool to involve primary school children in research processes to improve scientific literacy and the understanding of the scientific background of the research

For children, storytelling provides an appropriate and motivating approach to playfully acquire knowledge about the main principles of science while taking part in a particular research process. In 2013, a school-based project was initiated as part of a research project investigating seed predation along an urban-rural gradient [Miczajka, Klein and Pufal, 2015]. In six months, more than 300 primary school children participated in the project. One aim of the project was to provide children aged eight to ten years an insight into an interpretation of scientific findings. To this end, schoolchildren were engaged in typical activities during the various project phases, i.e. generating initial hypotheses, recording data, testing the reliability of the data and finally communicating the findings. The story with its central hero in the shape of a unisex virtual scientist served as a door opener to the children's attention. In the course of the project, the hero played its role in different contexts by solving different tasks. The unisex virtual scientist with long hair and a green coat holding a magnifier (evoking a detective) was searching for evidence on seed predation on schoolyards and asked the children for support, while incidentally providing insights into the main principles of science (i.e. study design, data quality, ongoing research processes). The supervising scientists used stories to explain abstract scientific terms and concepts during the different phases of the research process and integrated the virtual scientist into real tasks for the children. Behavioural observations and verbal and written statements provided by the children in class [unpublished questionnaire data, compare the measurement of attention after Helmke and Renkl, 1992] suggest that the children were attentive to the narrative story of the scientist examining seed predation on schoolyards. Starting a class by telling a story might operate as a door opener as storytelling offers an easy and child-oriented way to understand complex issues. The story certainly enabled the children to feel part of the scientific project on an equal footing with the scientist's contribution. It also made them aware that real scientific inquiry requires the power of many, as children's manpower was explicitly requested. Furthermore, a scientist explaining first hand (as presented by real scientists) the detailed research work and the different tasks of the daily routine helped develop the children's ability to think about science and in a scientific way. 
In the context of citizen science, storytelling as a means of learning about science with real scientific tasks surely presents a more realistic way than often presented in comics or fictive children's film (unpublished questionnaire data).

\section{Case study 3: Storytelling as an agent to convey messages}

Storytelling proved to act as an ideal agent to transport findings of a citizen science project. In the presented case study, stories helped communicate the results of citizen science activities to the public with great plasticity, authenticity and fun. The project "Visible Science" conducted at the Konrad Lorenz Research Station in Upper Austria (KLF, a Core Facility of the University of Vienna, Austria) aimed to understand the behavioural mechanisms of avian social life by combining long-term monitoring of individually marked animals with short-term experimental setups [Frigerio et al., 2018; Puehringer-Sturmayr et al., 2018]. Within the frame of the Austrian funding scheme Sparkling Science, promoted by the Austrian Federal Ministry of Science, Education and Research, researchers of the KLF involved pupils in the long-term monitoring of behavioural patterns of the avian model species. So far, research questions addressed the relationship between social behaviour and physiology in Greylag geese and Northern Bald Ibises [Hirschenhauser, Frigerio and Neuböck-Hubinger, 2016]. The studies were carried out between 2010 and 2017 in cooperation with approximately 250 students aged 5 to 17 , supervised by eleven teachers from kindergartens and primary to secondary schools. Within the scope of the projects, pupils employed storytelling in a junior science slam performance to tell the public what their research topic was about, what they did and how they liked it. The pupils played the role of junior scientists explaining the aims of the project and their role to the audience. Their performance won the first price.

\section{From case studies to a generalized model}

By combining the set of categories (see Figure 4) and performing stepwise abstractions, we derived a generalized model (see Figure 5). The generalized model describes the central linkages between citizens and science through storytelling. In this model, citizen science facilitates interactions between people and science, whereas stories are interchangeably applied as an objective, tool and/or agent. In this framework, the narratives in storytelling act as connecting elements, as co-operator to achieve the goals of the citizen science project. The model visualizes a "shortcut" between science and society that is created through storytelling. The model stands for the connection of individuals or communities and how stories enable engagement in science and society.

Discussion

Our research confirms that storytelling represents a central aspect in today's citizen science practice, at least in the three German-speaking countries investigated and that it fulfils serval functions to achieve the aims and goals of citizen science projects. The application of stories ranges from being a research objective itself, a tool integrated in different phases of the research process to an agent to transport, e.g., findings and information. As shown in our case studies, stories can be useful during several phases of a citizen science project, from framing the research 


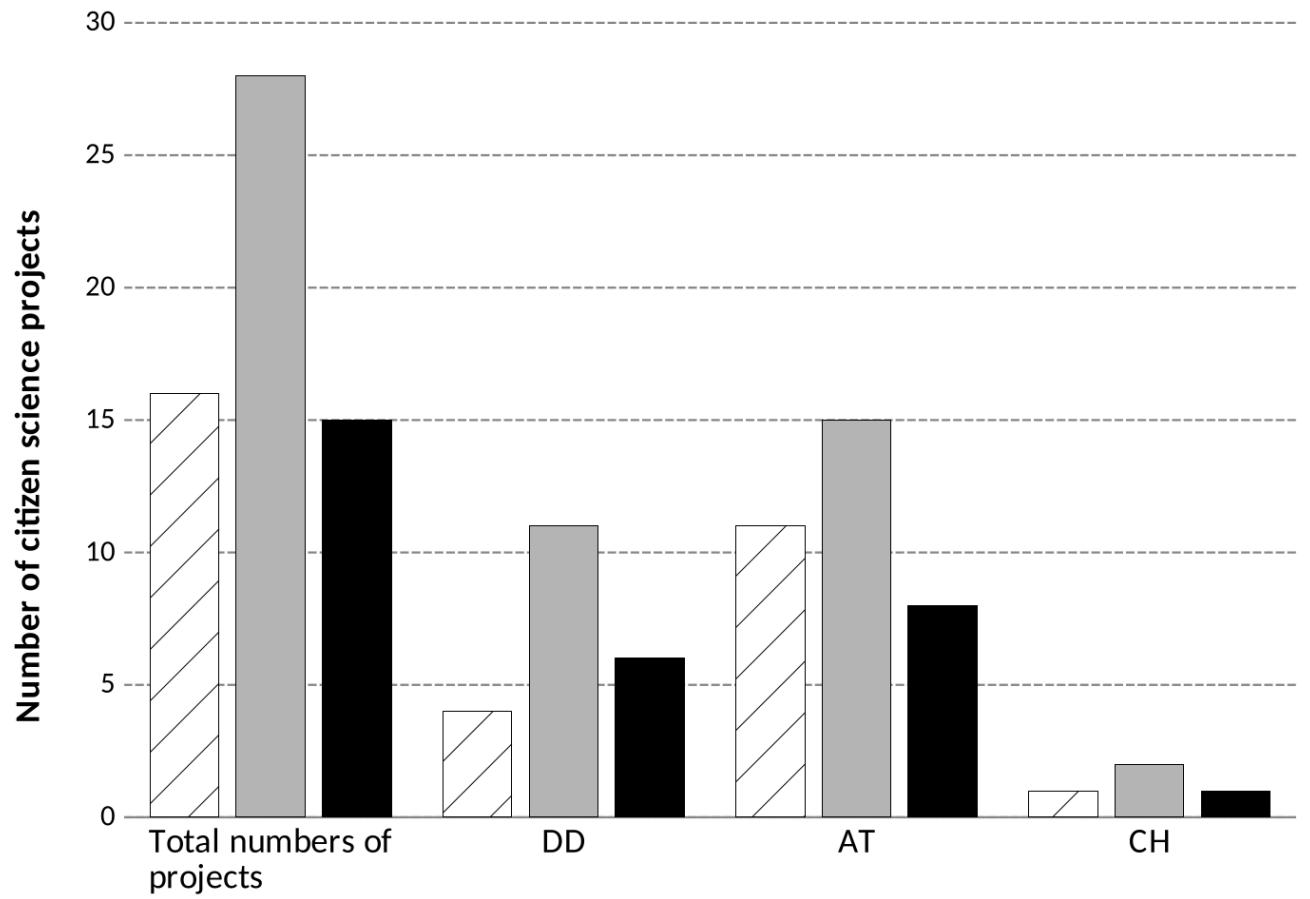

Distribution of categories (for all projects, per country)

$\square$ ST objective $\square$ ST tool $\square$ ST agent

Figure 4. Application of storytelling (ST) in citizen science for all investigated projects $(n=209)$ along the three categories (objective, tool, agent) and for each country.

question to the discussion and dissemination of the results. By conceptualizing the functionality of storytelling in citizen science we were able to highlight one of the benefits of stories: they can provide shortcuts to bridge science and society. From our findings, we derived five different features of stories that can serve as an explanation for the prominence of narratives in today's citizen science practice.

First, we learned that stories cross time scales. Thus, telling a story can easily bridge narratives from yesterday, today and tomorrow. As many projects take place over months, years and even decades, stories can act as agents to display views, perspectives, experiences and thoughts over longer periods. This feature is decidedly useful for the communication between the participants but also communication with external audiences. At any time, stories easily connect people [Meininger, 2010; Ioffreda and Gargiulo, 2008] and generations [Ryan et al., 2004]. Without people sharing a general interest in scientific endeavours, citizen science would not exist. Thus, stories also reflect and express the culture of science and the identity of a community at a certain time window [Robin, 2015].

Second, as shown in our typology of stories and the applications of these types in today's citizen science practice, stories can be applied very well to communicate the results generated in citizen science projects. Stories transfer knowledge and simultaneously foster social relationships [Nicklas et al., 2017]. These relationships are beneficial for the people involved and the narratives are essential to communicate vividly and intelligibly. Therefore, storytelling stimulates reflection 


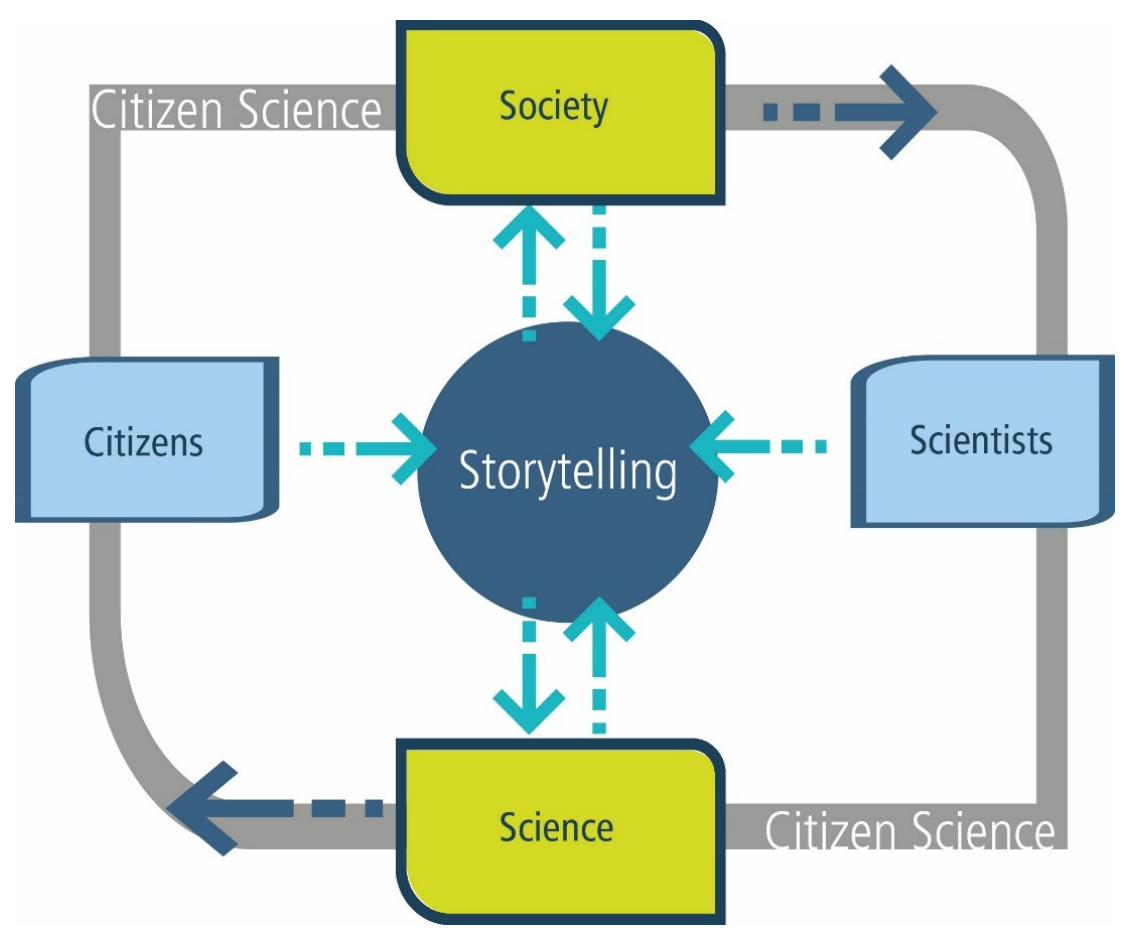

Figure 5. Generalized model of storytelling in citizen science based on the functions of storytelling in citizen science providing a visual representation of the various interactions in play. The outer arrows indicate how citizen science, understood as engagement in scientific processes, connects society with science and through its actors (citizens, scientists). Storytelling creates shortcuts among these actors.

and offers ways to learn about complex issues such as biodiversity [Wilson, 2002]. Furthermore, stories facilitate the opportunity to develop an understanding of a specific problem, linking it to the experiences of the person listening to the story and, thus, motivate that person to participate in future citizen science projects.

Third, storytelling is multi-functional, because it can be used both as an object (i.e., stories as carriers of knowledge/data - two-way communication) as well as a method (i.e., in/out communication). This multi-functionality is advantageous as citizen science is a dynamic process and adaptability is needed to fulfil scientific but also societal needs.

Fourth, storytelling is a valuable tool to foster the dialogue between science and society. Constant and Roberts [2017] define science communication as a process fully embedded in the research projects with 'engaged' methodologies rather than something occurring in one-off initiatives of science communication. Therefore, they consider narrative a tool to gain "access to the types of meaningful engagement and critical reflection amongst participants that science communication activities strive towards" [Constant and Roberts, 2017]. When researchers apply storytelling, they are challenged to experience alternative methods of communication, leaving the known methodological scientific tracks and developing an imagination for something new [Kleining, 1995]. However, we also need to consider that the way stories are told has a great effect on people's perception of science. Indeed, most people seem to have a set of expectations they await from a story, the scientific story being no exception. This may include a certain order of events, 
some resolution, which eventually restores order and balance, and the inference of causality or even teleology within the story [Todorov, 1969; Terrell, 1990].

Fifth, storytelling generates implicit and explicit knowledge. This confirms Polany's theory [1985], which postulates that implicit knowledge is a subjective form of knowledge that encompasses both cognitive and practical skills and underlies our everyday actions. Implicit knowledge is, therefore, mainly acquired through experience. Explicit knowledge is the theoretical and abstract factual knowledge that can be written down, stored and retrieved at any time. Explicit knowledge is objective and in principle a reproducible form of knowledge that can be assigned to the scientific tradition of the concept of knowledge [Dienes and Perner, 1999]. In this respect, the narrative is a creative medium for the generation of experience in projects. On the other hand, implicit knowledge is mainly based on individual and subjective experiences acquired in everyday dealings with people, belongings and events. This empirical knowledge is seen as a social and cultural construction [Berger and Luckmann, 1977], which represents a procedural event taking place in dependence on space, time and culture. Both processes of knowledge generation and knowledge transfer cannot be separated from the knowledge carriers and their symbolic orders. Storytelling can be the hub for generating implicit and explicit knowledge and, thus, holds great potentials.

Overall, the manifold features of storytelling form multiple means adaptable in many contexts in citizen science. It can be assumed that the interest in participating in citizen science reflects people's desire to live in a world where they belong to something. Storytelling is a mediator that allows this desire to become reality and that facilitates the development of a sense of belongingness through citizen science. Further, storytelling can be seen as a vehicle that, in the first place, shares common knowledge and makes perspectives and mentalities visible. Through storytelling, diverse views, opinions, knowledge domains and mindsets are brought together at the individual as well as the community level [Multisilta and Niemi, 2019].

\section{Conclusion}

We learned that storytelling is noticeable in the practice of citizen science but the term itself is not prominently placed in many of the German-speaking project presentations or information material. Different German words may be used to describe the concept of storytelling. We explain this by a possible knowledge gap regarding this scientific format, e.g. in science education and science communication (see introduction), and potentially also by language barriers. Here, we propose further investigations about the integration of the term and the approach in English-speaking projects and in projects that are performed in other languages than English or German. To enhance the recognition of the format of storytelling in today's citizen science practice, we postulate ongoing debates around storytelling as part of the discourses in citizen science. For prospective development of the generalized model provided, we call upon the scientific communities as well as the citizen science practitioners to consider the following next steps.

First, advance the pathways that are (dis)connecting the functions of storytelling in citizen science (objectives, tools, agents as shown in Figure 3) through theoretical and practical investigations. Understanding storytelling in citizen science requires better knowledge about storytelling as a means to convey stories. As shown in our 
analysis, stories take up questions and can be seen as a theoretical construct to reveal the impact of narratives on science, society and policy. Thus, research improving the understanding of the flows between and among the functions is needed to advance the model.

Second, we consider further investigations about measures of quality of each of these functions as well as targeted research on their effectiveness. Further, we suggest substantiating the model with future research through additional in-depth research of citizen science projects deriving from various countries and disciplines. Remaining theoretical limitations of the model, i.e., the level of stability of the model over time and space, should be addressed in the future. Storytelling is frequently context-related and often linked to a specific topic at a small scale (local, regional). Thus, the question of how temporal and spatial scales matter in the context of storytelling seems highly suitable for future investigations.

Further, storytelling opens up new theoretical and practical resources in citizen science, as narratives can convey complex individual and collective experiences in a vivid, emotional and practical way [Echterhoff and Straub, 2003]. As narratives provide treasured answers to 'why' and 'how', these aspects cherish the great potential of important research questions in the field of citizen science and science communication. Finally, as we gradually recognize the multi-functional, multi-layered and multi-faceted nature of storytelling in citizen science, we are just becoming aware of the systemic nature of storytelling whilst applying it on a daily base in our lives as citizens, scientists and citizen scientists.

Acknowledgments The networking between the authors and experts was possible thanks to a COST Action (151212) "Citizen Science to promote creativity, scientific literacy, and innovation throughout Europe" for a ten-day research stay of AS and DF in the working group of Prof Aletta Bonn (Helmholtz Centre for Environmental Research - UFZ and German Centre for Integrative Biodiversity Research (iDiv) Halle-Jena-Leipzig) in February 2018. The projects "The year of the Greylag geese" and "Social alliances and the flying area in Northern Bald Ibis" acknowledge A. Bisenberger, G. Gegendorfer, J. Hemetsberger, K. Kotrschal, M. Loretto and V. Pühringer-Sturmayr for valuable contributions to the research. Special thanks go to J. Sieberer, P. Cela and the directors and teachers as well as to the students of the schools involved in both projects. The initiators of the school-based research project investigating seed predation along an urban-rural gradient acknowledge all participating children and teachers contributing to scientific insight at multiple levels. Further, VMR is very grateful to Gesine Pufal and Brunhild Landwehr for their support with research in the context of citizen science and science education in primary schools. We thank the workshop participants Dario Martinelli (Lithuania), Nora Salas (Spain), Hannah Stockwell (U.K.) and Francesca de Chiara (Italy) for sharing their experiences in citizen science. We further thank the two research assistants Anne Chluppka and Larissa Schwaiger for collating information about the projects. Thank you also to Kati Kiezmann who kindly helped with the language and provided much-appreciated feedback to improve the readability of our research. We are grateful for the comments and suggestions provided by two anonymous reviewers. Financial support came from the German Centre for Integrative Biodiversity Research Halle-Jena-Leipzig, funded by the Deutsche Forschungsgemeinschaft (FZT 118). 
Appendix A. List of citizen science projects investigated
Table 1: List of citizen science projects integrating storytelling (ST) as objective, tool or/ and agent from Austria (AT), Switzerland (CH) and Germany (DE). Information is provided for each project indicating the function of application of storytelling (fourth column) and how this function is expressed and indicated in the projects (last column).

\begin{tabular}{|c|c|c|c|c|}
\hline Nr. & Name of the Project & Country & Function of ST & Expressed as/indicated by \\
\hline 1 & Turmfalke & AT & agent & $\begin{array}{l}\text { using pictures and associated stories to } \\
\text { share results }\end{array}$ \\
\hline 2 & Vielfalt bewegt & AT & agent & $\begin{array}{l}\text { stories (about species) are presented for } \\
\text { memorization }\end{array}$ \\
\hline 3 & Naturbeobachtung & AT & agent & $\begin{array}{l}\text { forum to exchange experiences, ideas, } \\
\text { stories }\end{array}$ \\
\hline 4 & Visible Science & AT & agent & $\begin{array}{l}\text { transporting research findings of beha- } \\
\text { vior studies to people }\end{array}$ \\
\hline 5 & Bienencheck & AT & agent & bee-stories to inform the community \\
\hline 6 & Code-It & AT & agent & $\begin{array}{l}\text { sharing knowledge and experiences with } \\
\text { and for the community }\end{array}$ \\
\hline 7 & Kultur in der Flur & AT & agent & $\begin{array}{l}\text { transporting stories saved for future gen- } \\
\text { erations }\end{array}$ \\
\hline 8 & Who cares & AT & agent & $\begin{array}{l}\text { stories as part of the project communica- } \\
\text { tion }\end{array}$ \\
\hline 9 & Reden Sie mit & AT & objective & $\begin{array}{l}\text { stories about accidental injuries are ana- } \\
\text { lyzed }\end{array}$ \\
\hline 10 & $\begin{array}{l}\text { Gesichter der } \\
\text { Migration }\end{array}$ & AT & objective & $\begin{array}{l}\text { writing stories about the personal his- } \\
\text { tory of migration }\end{array}$ \\
\hline 11 & Smile & AT & objective & analysis of stories \\
\hline 12 & Pollentagebuch & AT & objective & analysis of personal stories \\
\hline 13 & Bienenstand & $\mathrm{AT}$ & objective & collection of experiences by beekeepers \\
\hline 14 & Brotzeit & AT & objective & $\begin{array}{l}\text { ensuring and analyzing stories on local } \\
\text { knowledge and handcraft skills }\end{array}$ \\
\hline 15 & Topothek & AT & objective & $\begin{array}{l}\text { platform to secure local knowledge and } \\
\text { local stories }\end{array}$ \\
\hline 16 & Care and Heat & $\mathrm{AT}$ & objective & $\begin{array}{l}\text { write request to receive stories for ana- } \\
\text { lysis }\end{array}$ \\
\hline 17 & Yapes & $\mathrm{AT}$ & objective & $\begin{array}{l}\text { personal experiences and stories collec- } \\
\text { ted for analysis }\end{array}$ \\
\hline 18 & Kultur in der Flur & $\mathrm{AT}$ & objective & $\begin{array}{l}\text { stories about cultural heritage being in- } \\
\text { vestigated }\end{array}$ \\
\hline 19 & Who cares & $\mathrm{AT}$ & objective & $\begin{array}{l}\text { stories about the care of people being the } \\
\text { core research interest }\end{array}$ \\
\hline 20 & Stadt Land Kind & AT & tool & $\begin{array}{l}\text { using visual and sensory ethnography } \\
\text { and intergenerational dialogues as meth- } \\
\text { ods }\end{array}$ \\
\hline 21 & $\begin{array}{l}\text { Gesichter der } \\
\text { Migration }\end{array}$ & AT & tool & $\begin{array}{l}\text { stories in an online booklet to report } \\
\text { about the findings }\end{array}$ \\
\hline 22 & Smile & AT & tool & $\begin{array}{l}\text { application of discussion rounds and } \\
\text { cartoons }\end{array}$ \\
\hline 23 & Homegrown & AT & tool & $\begin{array}{l}\text { stories provide information about eco- } \\
\text { system services in gardens }\end{array}$ \\
\hline 24 & Explore AT & AT & tool & $\begin{array}{l}\text { collection of examples of dialects and } \\
\text { pictures/ graphics }\end{array}$ \\
\hline 25 & Topothek & AT & tool & $\begin{array}{l}\text { writing stories about the history of a } \\
\text { company/ enterprise }\end{array}$ \\
\hline 26 & Care and Heat & AT & tool & $\begin{array}{l}\text { cafe talks to gain information and know- } \\
\text { ledge }\end{array}$ \\
\hline 27 & $\begin{array}{l}\text { Zu Hause oder Fehl } \\
\text { am Platz }\end{array}$ & $\mathrm{AT}$ & tool & $\begin{array}{l}\text { Pictures and stories combined to express } \\
\text { cultural identity }\end{array}$ \\
\hline
\end{tabular}

Continued on the next page. 
Table 1: Continued from the previous page.

\begin{tabular}{|c|c|c|c|c|}
\hline Nr. & Name of the Project & Country & Function of ST & Expressed as/ indicated by \\
\hline 28 & Webtechniken & AT & tool & $\begin{array}{l}\text { new research questions formulated } \\
\text { based on shared experiences and stories } \\
\text { about weaving techniques }\end{array}$ \\
\hline 29 & $\mathrm{GeFaBe}$ & AT & tool & $\begin{array}{l}\text { documenting personal experiences for } \\
\text { future development of teaching material }\end{array}$ \\
\hline 30 & $\begin{array}{l}\text { Inside Trading } \\
\text { Cultures }\end{array}$ & AT & tool & $\begin{array}{l}\text { writing process to expand the perspect- } \\
\text { ives of citizens }\end{array}$ \\
\hline 31 & C.S.I. Pollen & AT & tool & $\begin{array}{l}\text { talking about the passion for bees to gain } \\
\text { insights into the culture of beekeeping }\end{array}$ \\
\hline 32 & Code-It & AT & tool & $\begin{array}{l}\text { identifying gaps from the stories being } \\
\text { told }\end{array}$ \\
\hline 33 & Politikradar & AT & tool & $\begin{array}{l}\text { descriptions with own words for further } \\
\text { analysis }\end{array}$ \\
\hline 34 & Who cares & AT & tool & $\begin{array}{l}\text { write request to receive stories for ana- } \\
\text { lysis }\end{array}$ \\
\hline 35 & $\begin{array}{l}\text { Tour de Suisse: din } \\
\text { dialäkt-ton accent }\end{array}$ & $\mathrm{CH}$ & agent & stories transport dialects investigated \\
\hline 36 & $\begin{array}{l}\text { Generation } \\
\text { Smartphone }\end{array}$ & $\mathrm{CH}$ & tool & $\begin{array}{l}\text { diaries about the use and the values of } \\
\text { smartphones }\end{array}$ \\
\hline 37 & $\begin{array}{l}\text { Schweizer Multiple- } \\
\text { Sklerose-Register }\end{array}$ & $\mathrm{CH}$ & tool & $\begin{array}{l}\text { diaries about the history of medical con- } \\
\text { ditions to memorize status and to gain } \\
\text { new knowledge }\end{array}$ \\
\hline 38 & Reden Sie mit & $\mathrm{CH}$ & objective & $\begin{array}{l}\text { stories about accidental injuries are ana- } \\
\text { lyzed }\end{array}$ \\
\hline 39 & Du kannst forschen & $\mathrm{DE}$ & agent & $\begin{array}{l}\text { transporting project findings to the com- } \\
\text { munity }\end{array}$ \\
\hline 40 & Reparakultur & $\mathrm{DE}$ & agent & $\begin{array}{l}\text { "Erzählkoffer" trolley full of stories } \\
\text { about repair culture }\end{array}$ \\
\hline 41 & $\begin{array}{l}\text { Historisches } \\
\text { Radfahrwissen }\end{array}$ & $\mathrm{DE}$ & agent & transport of knowledge via stories \\
\hline 42 & $\begin{array}{l}\text { Die } \\
\text { Familienforscher }\end{array}$ & $\mathrm{DE}$ & agent & $\begin{array}{l}\text { stories transporting historic knowledge } \\
\text { about games, work procedures, fairy } \\
\text { tales) }\end{array}$ \\
\hline 43 & $\begin{array}{l}\text { Archäologisches } \\
\text { Spessart-Projekt }\end{array}$ & $\mathrm{DE}$ & agent & $\begin{array}{l}\text { stories being applied to educate and } \\
\text { communicate cultural heritage }\end{array}$ \\
\hline 44 & Apfelblütenaktion & $\mathrm{DE}$ & agent & $\begin{array}{l}\text { stories embedded in videos to reach out } \\
\text { to participants }\end{array}$ \\
\hline 45 & $\begin{array}{l}\text { Forschungsfall } \\
\text { Nachtigall }\end{array}$ & $\mathrm{DE}$ & objective & $\begin{array}{l}\text { stories, songs, and poems collected for } \\
\text { analysis about the cultural history of the } \\
\text { birds }\end{array}$ \\
\hline 46 & Reden Sie mit & $\mathrm{DE}$ & objective & $\begin{array}{l}\text { stories about accidental injuries are ana- } \\
\text { lyzed }\end{array}$ \\
\hline 47 & $\begin{array}{l}\text { Historisches } \\
\text { Radfahrwissen }\end{array}$ & $\mathrm{DE}$ & objective & $\begin{array}{l}\text { collection of stories, books, maps to un- } \\
\text { derstand the history of cycling }\end{array}$ \\
\hline 48 & $\begin{array}{l}\text { Opfer der } \\
\text { NS-Euthanasie }\end{array}$ & $\mathrm{DE}$ & objective & $\begin{array}{l}\text { life stories and histories of suffering and } \\
\text { death to give dignity to those who were } \\
\text { victims and to process history }\end{array}$ \\
\hline 49 & Bremer Kogge & $\mathrm{DE}$ & tool & $\begin{array}{l}\text { stories applied for maintenance of the } \\
\text { culture of memories }\end{array}$ \\
\hline 50 & Sturmfluten & $\mathrm{DE}$ & tool & $\begin{array}{l}\text { stories applied for the maintenance of } \\
\text { the culture of memories }\end{array}$ \\
\hline 51 & Landinventur & $\mathrm{DE}$ & tool & $\begin{array}{l}\text { stories as part of a collective spatial ob- } \\
\text { servation }\end{array}$ \\
\hline
\end{tabular}

Continued on the next page. 
Table 1: Continued from the previous page.

\begin{tabular}{|c|c|c|c|c|}
\hline Nr. & Name of the Project & Country & Function of ST & Expressed as/ indicated by \\
\hline 52 & Transformationsstadt & $\mathrm{DE}$ & tool & $\begin{array}{l}\text { places of "good life" being mapped with } \\
\text { the assistance of stories (local everyday } \\
\text { knowledge) }\end{array}$ \\
\hline 53 & Bee observer & $\mathrm{DE}$ & tool & $\begin{array}{l}\text { gain insights into bees through stories } \\
\text { provided by beekeepers }\end{array}$ \\
\hline 54 & Reparakultur & $\mathrm{DE}$ & tool & $\begin{array}{l}\text { cultural probes (own stories, diaries, } \\
\text { videos, pics shared) to gain knowledge } \\
\text { about the group's culture, behaviors, } \\
\text { and attitudes }\end{array}$ \\
\hline 55 & $\begin{array}{l}\text { Genealogisches } \\
\text { Postkartenarchiv }\end{array}$ & $\mathrm{DE}$ & tool & $\begin{array}{l}\text { digitalization of stories at the back of } \\
\text { postcards to gain and secure knowledge } \\
\text { about the daily life of ordinary people }\end{array}$ \\
\hline 56 & $\begin{array}{l}\text { Umweltwiki } \\
\text { Sachsen }\end{array}$ & $\mathrm{DE}$ & tool & $\begin{array}{l}\text { write request about engagement in en- } \\
\text { vironmental activism }\end{array}$ \\
\hline 57 & $\begin{array}{l}\text { Landschaft im } \\
\text { Wandel }\end{array}$ & $\mathrm{DE}$ & tool & $\begin{array}{l}\text { perception of landscape changes } \\
\text { through postcards and stories }\end{array}$ \\
\hline 58 & $\begin{array}{l}\text { Expedition } \\
\text { Münsterland }\end{array}$ & $\mathrm{DE}$ & tool & $\begin{array}{l}\text { stories about local knowledge and every- } \\
\text { day situations to generate new know- } \\
\text { ledge }\end{array}$ \\
\hline 59 & $\begin{array}{l}\text { Die große } \\
\text { Hirschkäferjagd }\end{array}$ & $\mathrm{DE}$ & tool & postcards and stories about stag beetles \\
\hline
\end{tabular}

\section{References}

Barrett, H. (2006). 'Researching and evaluating digital storytelling as a deep learning tool'. In: Proceedings of SITE 2006. Society for Information Technology $\mathcal{E}$ Teacher Education International Conference. Ed. by C. Crawford, R. Carlsen, K. McFerrin, J. Price, R. Weber and D. Willis. Orlando, FL, U.S.A.: Association for the Advancement of Computing in Education (AACE), pp. 647-654. URL: http://www. learntechlib.org/primary/p/22117/ (visited on 9th April 2019).

Berger, P. and Luckmann, T. (1977). Die gesellschaftliche Konstruktion von Wirklichkeit. Frankfurt am Main, Germany: Fischer.

Bonn, A., Richter, A., Vohland, K., Pettibone, L., Brandt, M., Feldmann, R., Goebel, C., Grefe, C., Hecker, S., Hennen, L., Hofer, H., Kiefer, S., Klotz, S., Kluttig, T., Krause, J., Küsel, K., Liedtke, C., Mahla, A., Neumeier, V., Premke-Kraus, M., Rillig, M. C., Röller, O., Schäffler, L., Schmalzbauer, B., Schneidewind, U., Schumann, A., Settele, J., Tochtermann, K., Tockner, K., Vogel, J., Volkmann, W., von Unger, H., Walter, D., Weisskopf, M., Wirth, C., Witt, T., Wolst, D. and Ziegler, D. (2016). Greenpaper citizen science strategy 2020 for Germany. Berlin, Germany: Helmholtz-Zentrum für Umweltforschung - UFZ, Deutsches Zentrum für Integrative Biodiversitätsforschung (iDiv) Halle-Jena-Leipzig Leipzig, Museum für Naturkunde, Leibniz-Institut für Evolutions- und Biodiversitätsforschung — MfN, Berlin-Brandenburgisches Institut für Biodiversitätsforschung (BBIB).

URL: http: //www . buergerschaffenwissen.de/sites/default/files/grid/20 17/11/20/gewiss_cs_strategy_englisch_0.pdf (visited on 11th April 2019).

Bonney, R., Phillips, T. B., Ballard, H. L. and Enck, J. W. (2015). 'Can citizen science enhance public understanding of science?' Public Understanding of Science 25 (1), pp. 2-16. https://doi.org/10.1177/0963662515607406. 
Bruner, J. S. (1996). The culture of education. Cambridge, MA, U.S.A.: Harvard University Press.

Burns, T. W., O'Connor, D. J. and Stocklmayer, S. M. (2003). 'Science Communication: A Contemporary Definition'. Public Understanding of Science 12 (2), pp. 183-202. https://doi.org/10.1177/09636625030122004.

Ceccaroni, L. and Piera, J. (2017). Analyzing the role of citizen science in modern research. Hershey, PA, U.S.A.: ICI Global.

Chinthamani, N. R. R. (2003). 'The cultural values of science'. In: Pontificia Academia Scientiarum Scripta Varia. Plenary session (8th November 2002-11th November 2002). Vol. 105. Vatican City: Pontificia Academia Scientiarum, pp. 209-212. URL: http://inters . org/Rao-Science-Culture (visited on 3rd April 2019).

Chung, S. K. (2007). 'Art education technology: digital storytelling'. Art Education 60 (2), pp. 17-22. https://doi.org/10.1080/00043125.2007.11651632.

Constant, N. and Roberts, L. (2017). 'Narratives as a mode of research evaluation in citizen science: understanding broader science communication impacts'. JCOM 16 (04), A03. https://doi.org/10.22323/2.16040203.

Dahlstrom, M. F. (2014). 'Using narratives and storytelling to communicate science with nonexpert audiences'. Proceedings of the National Academy of Sciences 111 (Supplement 4), pp. 13614-13620.

https://doi.org/10.1073/pnas.1320645111.

De Vecchi, N., Kenny, A., Dickson-Swift, V. and Kidd, S. (2016). 'How digital storytelling is used in mental health: a scoping review'. International Journal of Mental Health Nursing 25 (3), pp. 183-193. https://doi.org/10.1111/inm.12206.

Dernbach, B., Kleinert, C. and Münder, H., eds. (2012). Handbuch Wissenschaftskommunikation. Wiesbaden, Germany: Springer. https://doi.org/10.1007/978-3-531-18927-7.

Dienes, Z. and Perner, J. (1999). 'A theory of implicit and explicit knowledge'. Behavioral and Brain Sciences 22 (5), pp. 735-808. https://doi.org/10.1017/s0140525x99002186.

Echterhoff, G. and Straub, J. (2003). 'Narrative Psychologie: Facetten eines Forschungsprogramms'. Handlung, Kultur, Interpretation 12, pp. 317-342.

Edwards, R., Kirn, S., Hillman, T., Kloetzer, L., Mathieson, K., McDonnell, D. and Phillips, T. (2018). 'Learning and developing science capital through citizen science'. In: Citizen Science. London, U.K.: UCL Press, pp. 381-390. https://doi.org/10.2307/j.ctv550cf2.33.

Frigerio, D., Pipek, P., Kimmig, S., Winter, S., Melzheimer, J., Diblíková, L., Wachter, B. and Richter, A. (2018). 'Citizen science and wildlife biology: synergies and challenges'. Ethology 124 (6), pp. 365-377. https://doi.org/10.1111/eth.12746.

Göbel, C., Cappadonna, J., Newman, G., Zhang, J. and Vohland, K. (2016). 'More than just networking for citizen science. Examining core roles of practitioner organizations'. In: Analyzing the role of citizen science in modern research. Ed. by L. Ceccaroni and J. Piera. U.S.A.: IGI global. https://doi.org/10.4018/978-1-5225-0962-2.ch002.

Green, M. C. (2006). 'Narratives and cancer communication'. Journal of Communication 56 (Supplement 1), S163-S183. https://doi.org/10.1111/j.1460-2466.2006.00288.x.

Hagenhoff, S., Seidenfaden, L., Ortelbach, B. and Schumann, M. (2007). Neue Formen der Wissenschaftskommunikation. Göttingen, Germany: Universitätsverlag Göttingen. https : //doi .org/10.17875/gup2007-208. 
Hecker, S., Haklay, M., Bowser, A., Makuch, Z., Vogel, J. and Bonn, A. (2018). Citizen science: innovation in open science, society and policy. London, U.K.: UCL Press.

Hecker, S., Luckas, M., Brandt, M., Kikillus, H., Marenbach, I., Schiele, B., Sieber, A., van Vliet, A. J. H., Walz, U. and Wende, W. (2018). 'Stories can change the world - the innovative potential of citizen science communication'. In: Citizen science: innovation in open science, society and policy. Ed. by S. Hecker, M. Haklay, A. Bowser, Z. Makuch, J. Vogel and A. Bonn. London, U.K.: UCL Press.

Helmke, A. and Renkl, A. (1992). 'Das Münchner Aufmerksamkeitsinventar (MAI): Ein Instrument zur systematischen Verhaltensbeobachtung der Schüleraufmerksamkeit im Unterricht'. Diagnostica 38 (2), pp. 130-141.

Hinyard, L. J. and Kreuter, M. W. (2007). 'Using Narrative Communication as a Tool for Health Behavior Change: A Conceptual, Theoretical, and Empirical Overview'. Health Education \& Behavior 34 (5), pp. 777-792. https://doi.org/10.1177/1090198106291963.

Hirschenhauser, K., Frigerio, D. and Neuböck-Hubinger, B. (2016). ‘Wirkungen außerschulischer Angebote im Sachunterricht: Das Waldrapp-Projekt'. [Impact of external projects on teaching natural sciences in primary school: the northern bald ibis case]. Transfer Forschung-Schule 2, pp. 307-308.

Ingrisch, D., Mangelsdorf, M. and Dressel, G., eds. (2017). Wissenskulturen im Dialog. Experimentalräume zwischen Wissenschaft und Kunst. Bielefeld, Germany: Transcript Verlag.

Ioffreda, A. and Gargiulo, T. (2008). 'Who's telling stories?' Communication World 25, pp. 37-39.

Kahlert, J. (2005). 'Story Telling im Sachunterricht — Lernpotenziale von Geschichten'. In: Erfahrungswissen erzählbar machen - Narrative Ansätze für Wirtschaft und Schule. Ed. by G. Reinmann. Berlin, Germany, Rome, Italy and Vienna, Austria: Pabst Science Publishers.

Kleining, G. (1995). Lehrbuch entdeckende Sozialforschung. Band 1: Von der Hermeneutik zur qualitativen Heuristik. Weinheim, Germany: Beltz/PVU.

Kullenberg, C. and Kasperowski, D. (2016). 'What is Citizen Science? A Scientometric Meta-Analysis'. Plos One 11 (1), e0147152. https://doi.org/10.1371/journal.pone.0147152.

Kurth, L. A., Kidd, R., Gardner, R. and Smith, E. L. (2002). 'Student use of narrative and paradigmatic forms of talk in elementary science conversations'. Journal of Research in Science Teaching 39 (9), pp. 793-818.

https://doi.org/10.1002/tea.10046.

Lac, A. (2016). 'Content analysis'. In: Encyclopedia of adolescence. 2nd ed. Cham, Switzerland: Springer International Publishing, pp. 1-5. https://doi.org/10.1007/978-3-319-32132-5_783-1. (Visited on 12th November 2018).

Leggett, M. and Finlay, M. (2001). 'Science, story and image: a new approach to crossing the communication barrier posed by scientific jargon'. Public Understanding of Science 10 (2), pp. 157-171. https://doi.org/10.1088/0963-6625/10/2/301.

Mayring, P. (2010). 'Qualitative Inhaltsanalyse'. In: Handbuch Qualitative Forschung in der Psychologie. Ed. by G. Mey and K. Mruck. Germany: VS Verlag für Sozialwissenschaften, pp. 601-613. https://doi.org/10.1007/978-3-531-92052-8_42. 
Meininger, H. P. (2010). 'Connecting stories: a narrative approach of social inclusion of persons with intellectual disability'. Alter 4 (3), pp. 190-202.

https://doi.org/10.1016/j.alter.2010.04.001.

Miczajka, V. L., Klein, A.-M. and Pufal, G. (2015). 'Elementary school children contribute to environmental research as citizen scientists'. PLOS ONE 10 (11), e0143229. https://doi.org/10.1371/journal . pone.0143229.

Multisilta, J. and Niemi, H. (2019). 'Tools, pedagogical models and best practices for digital storytelling'. In: Advanced methodologies and technologies in modern education delivery. IGI Global, pp. 508-519. https://doi.org/10.4018/978-1-5225-7365-4.ch040.

Nicklas, D., Lane, J. L., Hanson, J., Owens, J. and Treitz, M. (2017). ‘Using digital stories to reflect on the culture of overuse, misuse and underuse in medicine and enhance the patient-provider relationship'. Academic Pediatrics 17 (6), pp. 694-696. https://doi .org/10.1016/j .acap. 2017.01.017.

Norris, S. P., Guilbert, S. M., Smith, M. L., Hakimelahi, S. and Phillips, L. M. (2005). 'A Theoretical Framework for Narrative Explanation in Science'. Science Education 89 (4), pp. 535-563. https://doi.org/10.1002/sce. 20063.

Osborne, J. (1998). Beyond 2000: science education for the future. A report with ten recommendations. London, U.K.: School of education, King's College. URL: https://www. nuffieldfoundation.org/sites/default/files/Beyond\%2 02000.pdf (visited on 10th April 2019).

Pettibone, L., Vohland, K. and Ziegler, D. (2017). 'Understanding the (inter)disciplinary and institutional diversity of citizen science: a survey of current practice in Germany and Austria'. PLOS ONE 12 (6), e0178778. https://doi.org/10.1371/journal . pone.0178778.

Polany, M. (1985). The tacit dimension. New York, NY, U.S.A.: Garden City.

Puehringer-Sturmayr, V., Wascher, C. A. F., Loretto, M.-C., Palme, R., Stoewe, M., Kotrschal, K. and Frigerio, D. (2018). 'Seasonal differences of corticosterone metabolite concentrations and parasite burden in northern bald ibis (Geronticus eremita): the role of affiliative interactions'. PLOS ONE 13 (1), e0191441. https://doi.org/10.1371/journal.pone.0191441.

Richter, A., Dörler, D., Hecker, S., Heigl, F., Pettibone, L., Sanz, F. S., Vohland, K. and Bonn, A. (2018). 'Capacity building in citizen science'. In: Citizen science. Ed. by S. Hecker, A. Bonn, M. Haklay, A. Bowser, Z. Makuch and J. Vogel. London, U.K.: UCL Press, pp. 269-283. https : //doi .org/10.14324/111.9781787352339.

Richter, A., Hauck, J., Feldmann, R., Kühn, E., Harpke, A., Hirneisen, N., Mahla, A., Settele, J. and Bonn, A. (2018). 'The social fabric of citizen science - drivers for long-term engagement in the German butterfly monitoring scheme'. Journal of Insect Conservation 22 (5-6), pp. 731-743. https://doi.org/10.1007/s10841-018-0097-1.

Robin, B. R. (2015). 'The effective uses of digital storytelling as a teaching and learning tool'. In: Handbook of research on teaching literacy through the communicative and visual arts. Vol. 2, pp. 429-440. https://doi.org/10.4324/9781315759616.ch43.

- (2016). 'The power of digital storytelling to support teaching and learning'. Digital Education Review 30, pp. 17-29.

URL: https://eric.ed.gov/?id=EJ1125504. 
Ryan, E. B., Pearce, K. A., Anas, A. P. and Norris, J. E. (2004). 'Writing a connection: intergenerational communication through stories'. In: Family stories and the life course: across time and generations. Ed. by M. W. Pratt and B. H. Fiese. New York, NY, U.S.A.: Routledge, pp. 1-24. https://doi.org/10.4324/9781410610300.

Shirk, J. L., Ballard, H. L., Wilderman, C. C., Phillips, T., Wiggins, A., Jordan, R., McCallie, E., Minarchek, M., Lewenstein, B. V., Krasny, M. E. and Bonney, R. (2012). 'Public Participation in Scientific Research: a Framework for Deliberate Design'. Ecology and Society 17 (2), p. 29. https://doi.org/10.5751/ES-04705-170229.

Skarlatidou, A., Hamilton, A., Vitos, M. and Haklay, M. (2019). 'What do volunteers want from citizen science technologies? A systematic literature review and best practice guidelines'. JCOM 18 (01), A02. https://doi.org/10.22323/2.18010202.

Strohmeier, G. and Sieber, A. (2017). BrotZeit. Lesachtaler Brot im intergenerationellen Dialog. URL: https://lesachtalerbrot.wordpress.com/.

Terrell, J. (1990). 'Storytelling and prehistory'. In: Archaeological method and theory. Ed. by M. B. Schiffer. Phoenix, AZ, U.S.A.: The University of Arizona Press.

Todorov, T. (1969). Grammaire du Décaméron. The Hague, The Netherlands: Mouton.

Trench, B. (2008). 'Towards an analytical framework of science communication models'. In: Communicating science in social contexts. Dordrecht, The Netherlands: Springer, pp. 119-135. https://doi.org/10.1007/978-1-4020-8598-7_7.

van der Hoeven, A. (2019). 'Historic urban landscapes on social media: the contributions of online narrative practices to urban heritage conservation'. City, Culture and Society 17, pp. 61-68. https://doi.org/10.1016/j.ccs.2018.12.001.

van Vliet, A. J. H., Bron, W. A. and Mulder, S. (2014). 'The how and why of societal publications for citizen science projects and scientists'. International Journal of Biometeorology 58 (4), pp. 565-577. https://doi.org/10.1007/s00484-014-0821-9.

Walters, T. and Insch, A. (2018). 'How community event narratives contribute to place branding'. Journal of Place Management and Development 11 (1), pp. 130-144. https://doi.org/10.1108/jpmd-09-2017-0089.

Weitkamp, E. (2016). 'Telling stories about our research'. JCOM 15 (02), E. https://doi.org/10.22323/2.15020501.

Wilson, E. O. (2002). 'The power of story'. American Educator 26 (1), pp. 8-11. URL: https://eric.ed.gov/?id=EJ660264.

Woods, A. (2011). 'The limits of narrative: provocations for the medical humanities'. Medical Humanities 37 (2), pp. 73-78. https://doi.org/10.1136/medhum-2011-010045.

Zabel, J. and Gropengießer, H. (2015). 'What can narrative contribute to students' understanding of scientific concepts, e.g. evolution theory?' Journal of the European Teacher Education Network 10, pp. 136-146.

URL: https://jeten-online.org/index.php/jeten/article/view/74 (visited on 10th April 2019). 
Anett Richter holds a PhD in applied sciences and conducts research at the interface of nature conservation, biodiversity, environmental education, and citizen science. She led the development of the Citizen Science Strategy 2020 for Germany collaboratively with partners from science, society and policy. Her research interests are understanding the role of participation in the development of policy instruments, social networks and science communication. Further, she investigates citizen science as a concept by looking at theoretical interfaces across disciplines. E-mail: anett.richter@thuenen.de.

Andrea Sieber has diplomas in landscape architecture, social management, social economy and pedagogy. Her research focuses on cultural sustainability and participatory research. She is active as a consultant in the FARO Network for Democratic Citizenship and Participation of the Council of Europe and in the team of the Austrian Citizen Science Platform "Österreich forscht".

E-mail: andrea.sieber@aau.at.

Julia Siebert studied biology, rhetoric, and philosophy. In her PhD, she assessed the effects of different global change drivers on soil organisms and their functions. Additional topics included epistemological work on paradigm shifts in science and evidence in biology. Her current research focusses on the transformative potential of participatory approaches at the interface of biodiversity research, school education, and environmental psychology. E-mail: julia.siebert@idiv.de.

Victoria Miczajka-Rußmann holds a PhD in biology, with a focus on ecosystem functions. By connecting citizen science with primary school teacher education in natural sciences, her research is partly determined by improving students' and teacher students understanding of the nature of science and the basic science concepts. Hereby she applies several teaching methodologies such as the approach of storytelling. E-mail: miczajka@uni-leipzig.de.

Jörg Zabel is a professor in Biology Didactics at Leipzig University (UL). After working as a grammar school teacher (2000-2003), he investigated the role of narrative for understanding evolution in his $\mathrm{PhD}$ thesis at Leibniz University Hannover. In 2011, he became a full professor at UL Life Science Faculty and has been leading the Biology Education workgroup since then. His research interests are teaching and learning evolution theory, biodiversity and bioethics, conceptual metaphor and narrative in science teaching. E-mail: joerg.zabel@uni-leipzig.de.

David Ziegler worked as a researcher and editor for the German citizen science platform "Bürger schaffen Wissen". He was responsible for building a network of researchers, citizens, and other stakeholders, developing and organizing workshops on key aspects of citizen science, including storytelling. His research interests focus on understanding the German citizen science landscape and quality aspects of citizen science. As a part-time performance artist, storytelling plays a central part in his everyday life. E-mail: david.ziegler@mfn.berlin. 
Susanne Hecker researches citizen science at the interface between science, society and politics and the role of communication in participative research projects. She has been instrumental in building the international citizen science network, organized the first European Citizen Science Conference in 2016 and is first editor of the book "Citizen Science - Innovation in Open Science, Society and Policy" published by UCL Press in 2018. As a trained science communicator, she is currently completing her doctorate in Citizen Science Communication. E-mail: susanne.hecker@idiv.de.

Didone Frigerio holds a PhD in biology. She is a behavioural biologist, her major topic of interest is the relationship between social context and physiology in birds. Valuable collaborators were in the last year pupils and students of Austrian schools involved in long-term monitoring activities. DF is further interested in the advantages generated by applying citizen science in behavioural biology as well as in the potential of science communication tools for successful cooperation among different disciplines. E-mail: didone.frigerio@univie.ac.at.

\section{How to cite}

Richter, A., Sieber, A., Siebert, J., Miczajka-Rußmann, V. L., Zabel, J., Ziegler, D., Hecker, S. and Frigerio, D. (2019). 'Storytelling for narrative approaches in citizen science: towards a generalized model'. JCOM 18 (06), A02. https://doi.org/10.22323/2.18060202. 